\title{
Atorvastatin attenuates $p$-cresyl sulfate-induced atherogenesis and plaque instability in ApoE knockout mice
}

\author{
HUI HAN ${ }^{1,2^{*}}$, YANJIA CHEN ${ }^{1,2^{*}}$, JINZHOU ZHU $^{1 *}$, JINGWEI NI $^{1}$, JIATENG SUN ${ }^{1,2}$ and RUIYAN ZHANG ${ }^{1,2}$ \\ ${ }^{1}$ Department of Cardiology, Rui Jin Hospital, Shanghai Jiao Tong University School of Medicine; \\ ${ }^{2}$ Institute of Cardiovascular Diseases, Shanghai Jiao Tong University School of Medicine, Shanghai 200025, P.R. China
}

Received September 24, 2015; Accepted June 29, 2016

DOI: $10.3892 / \mathrm{mmr} .2016 .5626$

\begin{abstract}
PCS) is a protein-bound uremic toxin retained in the blood of patients with chronic kidney disease (CKD) As atherosclerosis is a primary cardiovascular complication for patients with CKD, the aim of the present study was to investigate the mechanisms underlying the aggravation of atherosclerosis by PCS. In addition, the effect of atorvastatin was assessed in reversing the effects of PCS. PCS was revealed to promote the initiation and progression of atherosclerosis. Following treatment with atorvastatin, apolipoprotein E knockout mice demonstrated a reduction in PCS-induced atherogenesis and plaque vulnerability. In addition, atorvastatin decreased the protein expression levels of vascular cell adhesion molecule-1 and intercellular cell adhesion molecule-1, and the interaction between leukocytes and endothelia. The plasma lipid profiles of mice were not significantly affected by gavage of low-dose atorvastatin. The results of the present study indicate that PCS promotes plaque growth and instability by enhancing leukocyte-endothelium interaction, and that these effects may be attenuated by atorvastatin treatment.
\end{abstract}

\section{Introduction}

Chronic kidney disease (CKD), which affects up to $15 \%$ of adults in the USA, presents a significant threat to public health (1-3). Diabetes mellitus, hypertension, glomerulonephritis and idiopathic origins are the most common causes. CKD is a primary risk factor for the development of cardiovascular diseases (CVDs) (4-6). Among various cardiovascular

Correspondence to: Dr Ruiyan Zhang, Department of Cardiology, Rui Jin Hospital, Shanghai Jiao Tong University School of Medicine, 197 Rui Jin 2nd Road, Shanghai 200025, P.R. China

E-mail: rjzhangruiyan@aliyun.com

*Contributed equally

Key words: uremic toxin, $p$-cresyl sulfate, vulnerable plaque, atorvastatin, atherosclerosis, leukocyte-endothelium interaction complications, atherosclerosis is predictive of a markedly increased risk of cardiovascular mortality in CKD patients (7). Notably, coronary heart disease is prevalent in CKD patients, whereas the survival rate following acute coronary syndrome (ACS) is decreased compared with the general population (8). As reported in a population-based prospective study of people lacking manifest vascular disease, even the earliest stages of CKD are associated with an increased risk of subsequent coronary heart disease (9). In addition, CKD patients suffer more severe atherosclerotic lesions in coronary plaques as renal function deteriorates (10). However, the underlying mechanisms linking these two diseases remain to be fully elucidated.

CKD is characterized by the retention of various uremic toxins, including the protein-bound solutes $p$-cresyl sulfate (PCS) and indoxyl sulfate (IS). Due to their protein-binding properties, PCS and IS are not efficiently removed from the circulation by traditional hemodialysis and continue to accumulate in CKD patients $(11,12)$. PCS and IS have been associated with cardiovascular mortality $(13,14)$. However, whether these toxins contribute to the process of CKD-associated ACS remains to be elucidated. Although CKD patients have a greater incidence of, and increased mortality due to, ACS, causal mechanisms underlying this association remain to be precisely defined (15). Clinical evidence suggests that the majority of acute cardiovascular events may be attributed to vulnerable atherosclerotic plaques $(16,17)$. As the erosion or rupture of unstable atherosclerotic plaques is a primary cause of ACS, it was hypothesized that protein-bound uremic toxins may disturb the stability of atherosclerotic plaques.

Statins, a class of drugs that inhibit 3-hydroxy-3-methylglutaryl coenzyme A reductase, are a first-line treatment for the primary and secondary prevention of atherosclerosis-associated CVD (18). In addition to decreasing serum cholesterol levels, statins have been demonstrated to be effective at improving endothelial function, reducing inflammation and promoting the stability of vulnerable atherosclerotic plaques (19). Therefore, it was hypothesized that atorvastatin, a member of the statin family, may attenuate the detrimental effects of protein-bound uremic toxins in the development of atherosclerosis.

The aim of the present study was to investigate the effect of excess PCS on the formation and stability of atherosclerotic plaques, using an apolipoprotein E knockout (ApoE KO) mouse model. In addition, the therapeutic potential of atorvastatin was carefully assessed. 


\section{Materials and methods}

Reagents and antibodies. PCS was synthesized using the method previously described by Feigenbaum and Neuberg (20). The identity and purity (>99\%) of PCS were confirmed using nuclear magnetic resonance spectroscopy. Atorvastatin was purchased from Pfizer, Inc. (Shanghai, China). Rat anti-mouse vascular cell adhesion molecule-1 (VCAM-1; catalog no. sc-18864), rat anti-mouse intercellular cell adhesion molecule-1 (ICAM-1; catalog no. sc-71303) and rabbit anti-mouse glyceraldehyde-3-phosphate dehydrogenase (GAPDH; catalog no. sc-25778) antibodies were purchased from Santa Cruz Biotechnology, Inc. (Dallas, TX, USA). Horseradish peroxidase (HRP)-conjugated rabbit anti-rat IgG (catalog no. 7077) and goat anti-rabbit IgG (catalog no. 7074) secondary antibodies were purchased from Cell Signaling Technology, Inc. (Danvers, MA, USA). Radioimmunoprecipitation assay buffer (RIPA lysis buffer), phenylmethanesulfonyl fluoride (PMSF) and bicinchoninic acid (BCA) protein assay kit were purchased from Beyotime Institute of Biotechnology (Shanghai, China).

Animals. Pathogen-free ApoE KO mice (C57BL/6 background, male, 8 weeks of age) were purchased from the Model Animal Research Center of Nanjing University (Nanjing, China). ApoE KO mice were maintained in air-filtered units at $21 \pm 2^{\circ} \mathrm{C}$ and $50 \pm 15 \%$ relative humidity under a 12 -h light/dark cycle. Animals were provided with a high-fat diet $(0.25 \%$ cholesterol and $15 \%$ cocoa butter) and sterile water ad libitum. Mice were randomly divided into three groups: i) Control group ( $n=16)$, in which mice received water by oral gavage; ii) PCS group $(\mathrm{n}=16)$, in which mice received $0.4 \% \mathrm{PCS}$ in water $(17 \mu \mathrm{l} / \mathrm{g})$ by oral gavage, to give a daily intake of $100 \mathrm{mg} / \mathrm{kg}$, as previously described $(21,22)$; and iii) PCS + atorvastatin group $(n=16)$, in which mice received $0.4 \% \mathrm{PCS}(17 \mu \mathrm{l} / \mathrm{g})$ by oral gavage and atorvastatin dissolved in isosmotic saline and infused via a stomach tube at a dose of $10 \mathrm{mg} / \mathrm{kg} / \mathrm{day}$, as previously described (23). Control and PCS groups were infused with equal volumes of isosmotic saline. Following 20 weeks of treatment, mice were sacrificed for further analyses. The study protocol was approved by the Committee on the Ethics of Animal Experiments of the Shanghai Jiao Tong University School of Medicine [Shanghai, China; permit no. (2012)-86]. Standards from the Guide for the Care and Use of Laboratory Animals by the National Institutes of Health (Bethesda, MD, USA; publication no. 85-23, revised 1996) were followed.

Tissue collection. Prior to collection of blood samples, animals were fasted overnight and anesthetized with $1.5 \%$ pentobarbital sodium (60 mg/kg i.p.; Shanghai XiTang Biotechnology Co., Ltd., Shanghai, China). Blood was collected from the inferior vena cava using a syringe and needle. Mice were perfused with ice-cold normal saline. The heart and arteries were dissected out. A portion of the samples was embedded in optimal cutting temperature compound, frozen and cut into 5- $\mu \mathrm{m}$ cryosections. For western blot analysis, tissue samples were immediately placed in liquid nitrogen. The samples were kept at $-80^{\circ} \mathrm{C}$ until use.

Biochemical investigations. The serum lipid profile of triglycerides (TG), total cholesterol (TC), low-density lipoprotein
Table I. Body weight and serum lipid profiles in the three mouse groups.

\begin{tabular}{lccc}
\hline & \multicolumn{3}{c}{ Group } \\
\cline { 2 - 4 } Parameter & $\begin{array}{c}\text { Ctrl } \\
(\mathrm{n}=8)\end{array}$ & $\begin{array}{c}\text { PCS } \\
(\mathrm{n}=8)\end{array}$ & $\begin{array}{c}\text { PCS+Ator } \\
(\mathrm{n}=8)\end{array}$ \\
\hline Body weight, g & $29.88 \pm 0.81$ & $31.25 \pm 0.80$ & $30.50 \pm 0.76$ \\
TC, mmol/1 & $20.55 \pm 0.66$ & $20.33 \pm 0.54$ & $19.96 \pm 0.59$ \\
TG, mmol/1 & $1.34 \pm 0.07$ & $1.32 \pm 0.06$ & $1.29 \pm 0.07$ \\
LDL-C, mmol/1 & $5.17 \pm 0.18$ & $5.21 \pm 0.18$ & $5.18 \pm 0.19$ \\
HDL-C, mmol/1 & $1.69 \pm 0.06$ & $1.71 \pm 0.07$ & $1.74 \pm 0.08$ \\
\hline
\end{tabular}

Data are expressed as the mean \pm standard error. Ctrl, control; PCS, $p$-cresyl sulfate; Ator, atorvastatin; TC, total cholesterol; TG, triglycerides; LDL-C, low-density lipoprotein cholesterol; HDL-C, high-density lipoprotein cholesterol.

cholesterol (LDL-C) and high-density lipoprotein cholesterol (HDL-C) were detected enzymatically using kits (catalog nos. 10010303 and 10007640; Cayman Chemical Company, Ann Arbor, MI, USA) according to the manufacturer's instructions.

Western blot analysis. Total protein was extracted from the aortas of ApoE KO mice. Briefly, protein extracts of the ascending aorta were homogenized in RIPA lysis buffer containing $1 \%$ PMSF. Following centrifugation of the homogenates at $14,000 \mathrm{x} \mathrm{g}$ for $30 \mathrm{~min}$ at $4^{\circ} \mathrm{C}$, supernatants were collected and protein concentrations assessed using a BCA protein assay kit. The supernatant was mixed with loading buffer and heated in a boiling water bath for $5 \mathrm{~min}$. Equal quantities $(50 \mu \mathrm{g})$ of prepared protein were subjected to $10 \%$ SDS-PAGE $(100 \mathrm{mV}$, $2 \mathrm{~h}$ ) and transferred onto polyvinylidene difluoride membranes. Membranes were blocked with 5\% non-fat milk in Tris-buffered saline with Tween-20 (Bio-Rad Laboratories, Inc., Hercules, CA, USA) and probed overnight at $4^{\circ} \mathrm{C}$ with antibodies recognizing ICAM-1 (1:1,000), VCAM-1 $(1: 1,000)$ and GAPDH $(1: 2,000)$ as previously described $(24,25)$. Membranes were then incubated with HRP-conjugated secondary antibodies at a dilution of 1:5,000 for $1 \mathrm{~h}$ at room temperature. Immunoreactive bands were detected using an Enhanced Chemiluminescence system (EMD Millipore, Billerica, MA, USA). The expression of ICAM-1 and VCAM-1 was normalized to GAPDH and quantified in Image-Pro Plus software version 6 (Media Cybernetics, Inc., Rockville, MD, USA).

Histology. The aorta was dissected and an aortic lesion en face assay was performed by staining with oil red $\mathrm{O}$ as previously described $(26,27)$. The percentage of lesion coverage was calculated by dividing the stained area by the total aortic surface area (28). In addition, aortic root analysis was performed. The collagen contents of the vascular intima were evaluated with Sirius red staining, using aortic root sections $(10 \mu \mathrm{m})$. Images were viewed and captured with an Olympus microscope (Olympus Corporation, Tokyo, Japan) and quantified in Image-Pro Plus software version 6.0. 
A

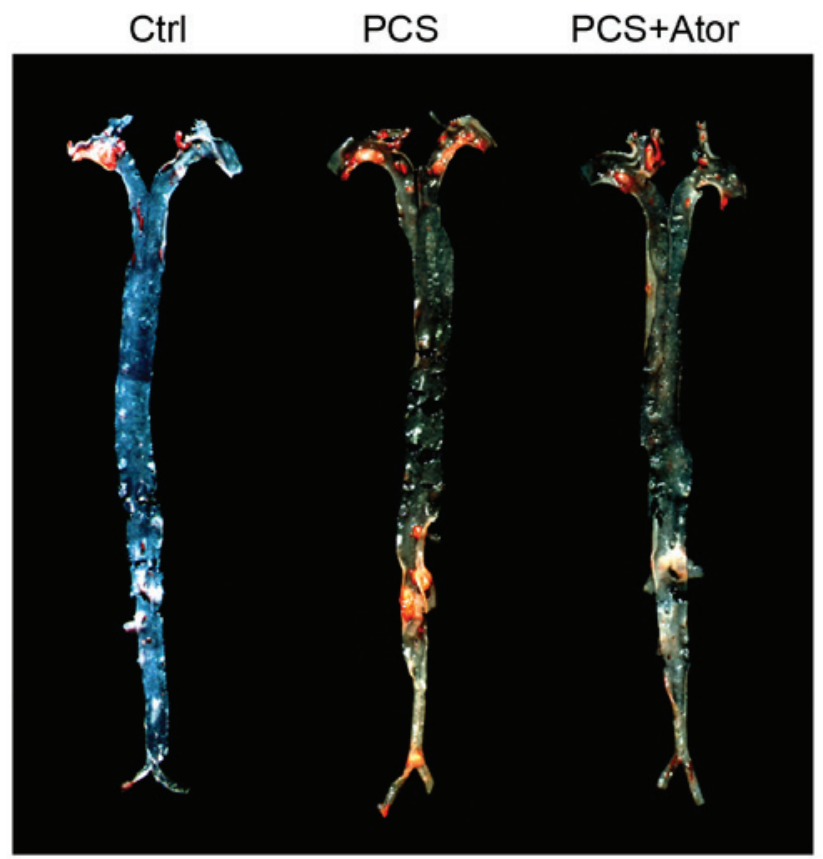

B

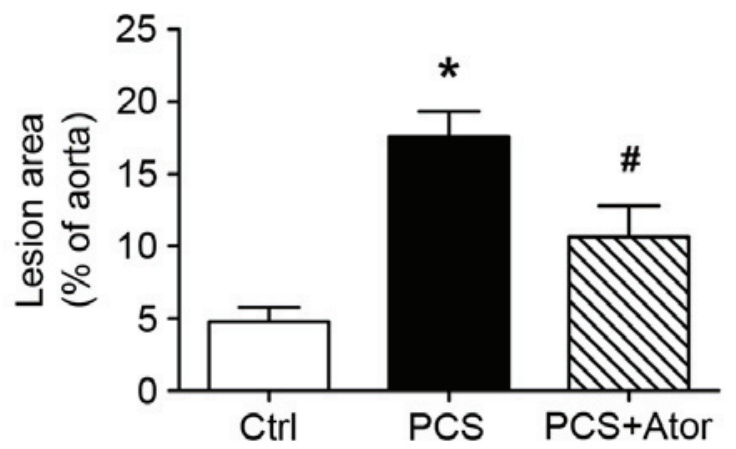

Figure 1. Mice treated with atorvastatin exhibit decreased atherosclerotic plaque areas following PCS administration. (A) Representative images of en face staining with oil red $\mathrm{O}$ in aortas from control mice, mice treated with PCS and mice treated with PCS and Ator. Red staining indicates atherosclerotic plaques. Scale bar $=5 \mathrm{~mm}$. (B) Quantitative analysis of lesion areas in Ctrl, PCS and PCS+Ator mice. Data are expressed as the mean \pm standard error $(\mathrm{n}=6-8)$. ${ }^{*} \mathrm{P}<0.05$ vs. Ctrl; ${ }^{*} \mathrm{P}<0.05$ vs. PCS. Ctrl, control; PCS, $p$-cresyl sulfate; Ator, atorvastatin.

Intravital microscopy. Following 20 weeks of treatment, an in vivo adhesion assay was performed as previously described $(25,29)$. Briefly, mice were anesthetized by i.p. injection of $60 \mathrm{mg} / \mathrm{kg}$ pentobarbital sodium. Leukocytes were labeled by retro-orbital injection of $50 \mu 10.05 \%$ Rhodamine 6G (Sigma-Aldrich, St. Louis, MO, USA). Mesenteric venules were exteriorized and rolling leukocytes were monitored using an inverted fluorescent microscope (Nikon Eclipse Ti; Nikon Corporation, Tokyo, Japan) equipped with a stage warmer (Thermo Plate; Tokai Hit Co., Ltd., Fujinomiya, Japan), a QuantEM:512SC camera (Photometrics, Tucson, AZ, USA), and a Nikon S Plan Fluor ELWD 20X objective (Nikon Corporation). Image-Pro Plus software version 6.2 (Media Cybernetics, Inc.) was used to automatically track real-time moving leukocytes. Leukocytes were classified as adherent or rolling, according to the quality or duration of their interaction with the venular wall. Leukocytes that were stationary for $>30 \mathrm{sec}$ were defined as adherent. The leukocyte rolling flux was defined as the total number of leukocytes crossing the $100-\mu \mathrm{m}$ venular segment in
1 min at a velocity that was significantly decreased compared with the centerline velocity. Leukocyte rolling velocity was determined by measuring the time required for a leukocyte to roll along a $100 \mu \mathrm{m}$ length of venule. Leukocyte adhesion is expressed as the number of cells $/ 100 \mu \mathrm{m}$ of venular length.

Statistical analysis. Data are expressed as the mean \pm standard error and were analyzed by paired or unpaired $t$-test unless otherwise stated. Differences between groups were analyzed by one-way analyses of variance followed by Student-Newman-Keuls post-hoc tests. $\mathrm{P}<0.05$ was considered to indicate a statistically significant difference. Data were analyzed in GraphPad Prism software version 5 (GraphPad Software, Inc., La Jolla, CA, USA).

\section{Results}

Atorvastatin attenuates PCS-induced atherogenesis in ApoE $K O$ mice. To evaluate the impact of PCS on atherogenesis 
A
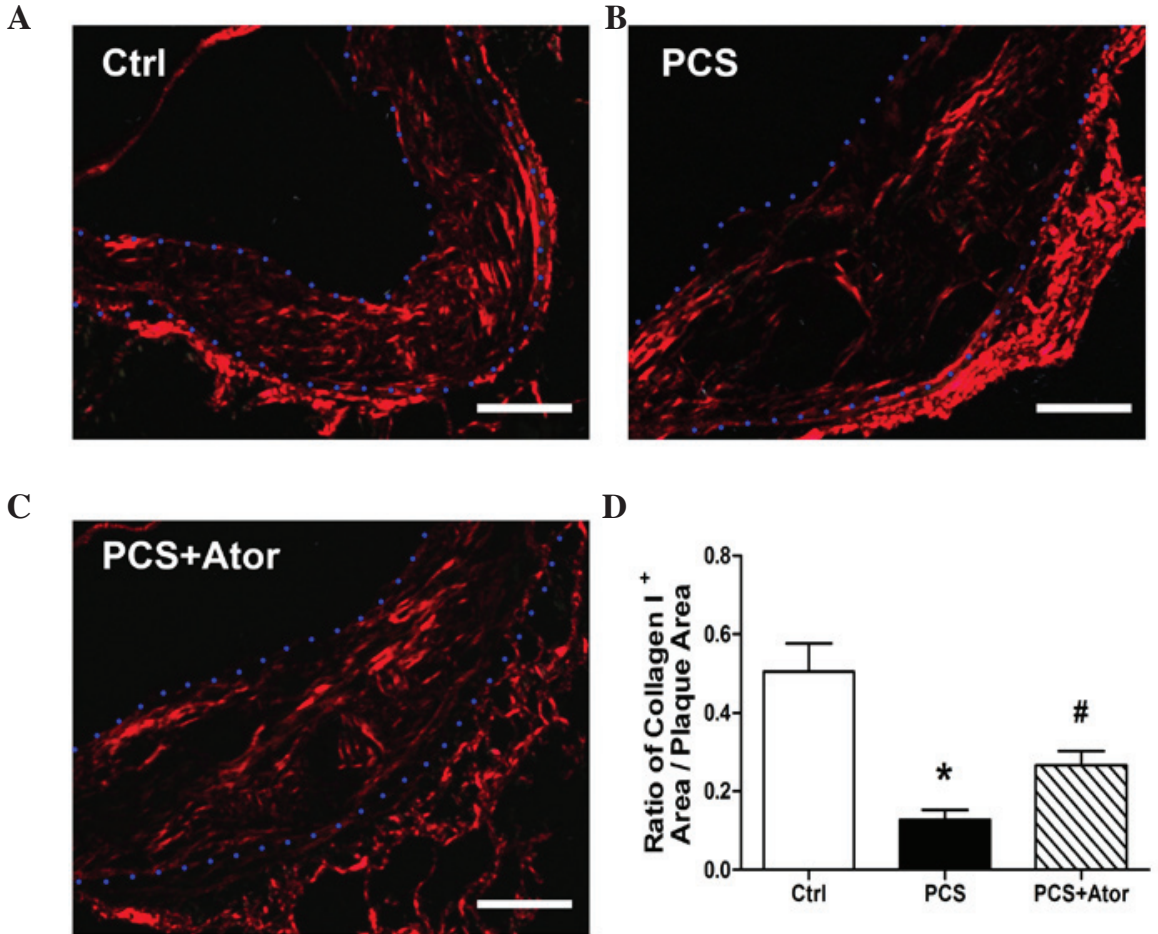

D

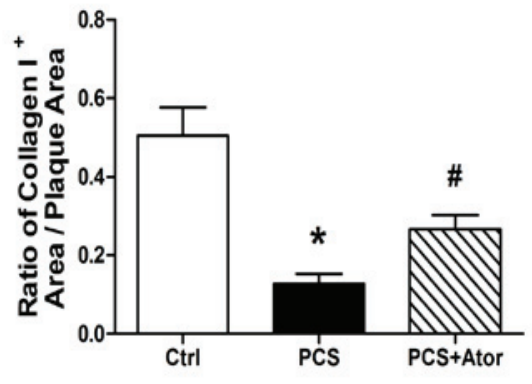

Figure 2. Mice treated with atorvastatin exhibit increased collagen I expression levels within atherosclerotic plaques following PCS administration. Representative images of Sirius red staining on aorta roots in (A) control mice, (B) mice treated with PCS and (C) mice treated with PCS and atorvastatin. Plaque areas are indicated by blue dots. Scale bars $=100 \mu \mathrm{m}$. (D) Quantitative analysis of collagen $\mathrm{I}^{+}$area/plaque area in Ctrl, PCS and PCS+Ator mice. Data are expressed as the mean \pm standard error $(\mathrm{n}=6-8)$. ${ }^{\mathrm{P}}<0.05$ vs. Ctrl; ${ }^{*} \mathrm{P}<0.05$ vs. PCS. Ctrl, control; PCS, $p$-cresyl sulfate; Ator, atorvastatin.

A
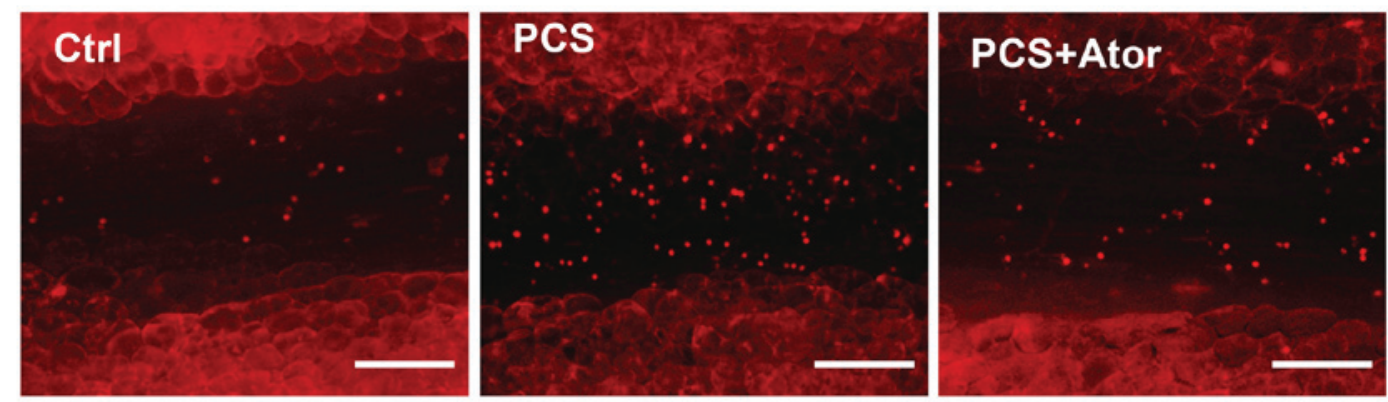

B

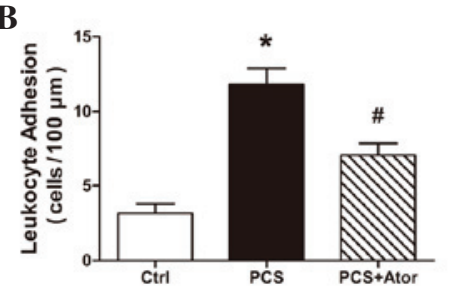

C

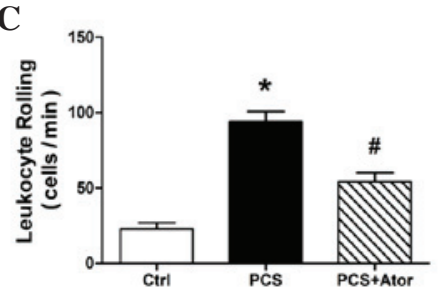

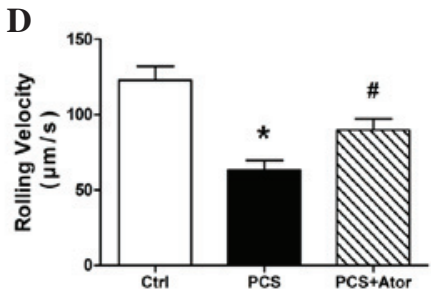

Figure 3. Mice treated with atorvastatin exhibit decreased leukocyte-endothelium interaction following PCS administration. (A) Representative images of rolling leukocytes within mesenteric venules in control mice, mice treated with PCS and mice treated with PCS and atorvastatin. Scale bars $=500 \mu$ m. Quantitative analysis of (B) adherent and (C) rolling leukocytes, and (D) leukocyte rolling velocity in Ctrl, PCS and PCS+Ator mice. Data are expressed as the mean \pm standard error $(\mathrm{n}=6-8)$. ${ }^{*} \mathrm{P}<0.05$ vs. $\mathrm{Ctrl} ;{ }^{*} \mathrm{P}<0.05$ vs. PCS. Ctrl, control; PCS, $p$-cresyl sulfate; Ator, atorvastatin.

in ApoE KO mice, aortas were dissected and en face gross examination by general oil red $\mathrm{O}$ staining was performed. Compared with control mice, increased atherosclerotic lesion sizes were observed in aortas from PCS-treated mice (17.60 \pm 1.74 vs. $4.75 \pm 1.03 ; \mathrm{P}=0.001$; Fig. 1). Atorvastatin treatment significantly abrogated the PCS-induced athero- 
$\mathbf{A}$

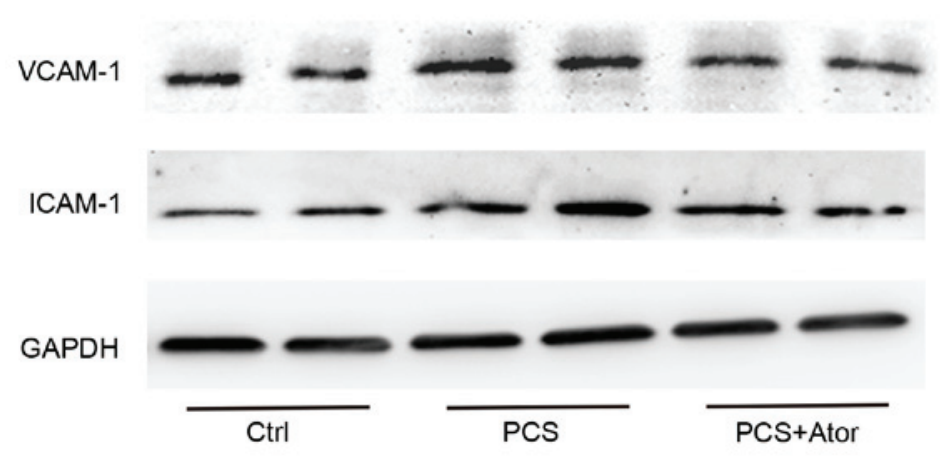

B

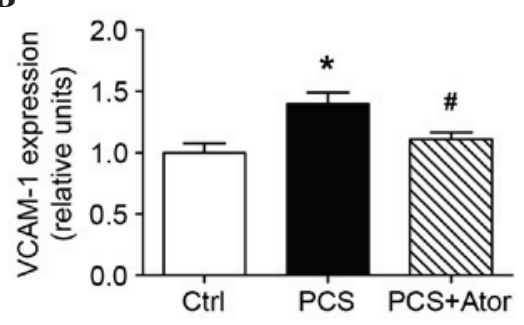

C

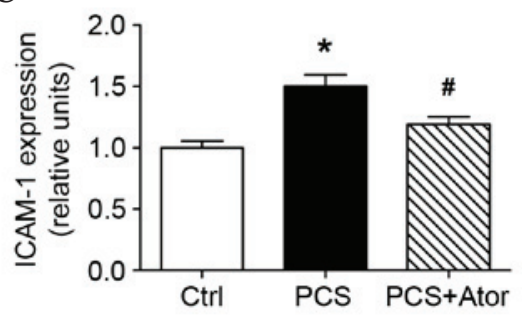

Figure 4. Mice treated with atorvastatin exhibit decreased protein expression levels of ICAM-1 and VCAM-1 following PCS administration. (A) Representative images of western blots reveal the protein expression levels of ICAM-1 and VCAM-1 in control mice, mice treated with PCS and mice treated with PCS and atorvastatin. Quantitative analysis of (B) VCAM-1 and (C) ICAM-1 band densities (normalized to GAPDH) in Ctrl, PCS and PCS+Ator mice. Data are expressed as the mean \pm standard error $(\mathrm{n}=6-8)$. ${ }^{*} \mathrm{P}<0.05$ vs. $\mathrm{Ctrl}$; ${ }^{*} \mathrm{P}<0.05$ vs. PCS mice. VCAM-1, vascular cell adhesion molecule-1; ICAM-1, intercellular cell adhesion molecule-1; Ctrl, control; PCS, $p$-cresyl sulfate; Ator, atorvastatin.

sclerotic plaque growth in aortas $(10.63 \pm 2.15 ; \mathrm{P}=0.03$ vs PCS alone). This therapeutic effect was independent of its lipid-reducing capacity, as low doses of atorvastatin did not significantly alter serum lipid profiles in experimental mice (Table I).

Atorvastatin inhibits the PCS-induced decrease in collagen expression levels in atherosclerotic plaques from ApoE $\mathrm{KO}$ mice. Histological analysis revealed that Sirius red-positive collagen I structures in atherosclerotic plaques were significantly decreased following 20 weeks of PCS administration (Ctrl, 0.51 \pm 0.07 ; PCS, 0.13 \pm 0.02 ; P=0.002; Fig. 2). This decrease was partially reversed by treatment with atorvastatin, which significantly augmented the ratio of collagen $\mathrm{I}^{+}$area/plaque area $(0.27 \pm 0.03 ; \mathrm{P}=0.005$ vs. $\mathrm{PCS})$.

Atorvastatin abrogates the PCS-induced increase in leukocyte-endothelium interaction in ApoE KO mice. Leukocyte adhesion to the endothelium is crucial for the early stages of atherogenesis. The impact of PCS on the leukocyte-endothelium interaction in the mesenteric venules of ApoE KO mice was therefore investigated. Compared with control mice, PCS mice demonstrated an increased leukocyte-endothelium adhesiveness, manifested by the increased rolling and adhering of leukocytes, and their decreased rolling velocity (all $\mathrm{P}<0.001$; Fig. 3). In mice treated with atorvastatin, however, the increased interaction between leukocytes and the endothelium was significantly abrogated (leukocyte adhesion, $\mathrm{P}=0.006$; leukocyte rolling, $\mathrm{P}=0.001$; and rolling velocity, $\mathrm{P}=0.021$ ).
Atorvastatin inhibits PCS-induced upregulated protein expression levels of VCAM-1 and ICAM-1 in aortas of ApoE KO mice. As adhesion molecules, VCAM-1 and ICAM-1 are involved in the interaction between circulating leukocytes and vascular endothelia. In the present study, the protein expression levels of these two molecules were significantly upregulated by PCS administration [by $1.402 \pm 0.089$-fold ( $\mathrm{P}=0.001$ vs. Ctrl) and 1.505 \pm 0.089 -fold ( $\mathrm{P}=0.007$ vs. $\mathrm{Ctrl})$, respectively; Fig. 4]; treatment with atorvastatin, however, protected against this [increases were $1.110 \pm 0.057$-fold $(\mathrm{P}=0.016$ vs. PCS) and $1.192 \pm 0.061$-fold ( $\mathrm{P}=0.020$ vs. $\mathrm{PCS})$, respectively].

\section{Discussion}

In the present study, PCS was demonstrated to promote endothelial-leukocyte adhesion, thereby accelerating atherogenesis and causing instability of atherosclerotic plaques in ApoE KO mice. However, atorvastatin partially reversed these PCS-induced effects.

Atherosclerosis is a complex process characterized by accumulation of lipids and fibrous elements in large arteries $(30,31)$. Increasing evidence suggests that the occurrence of acute cardiovascular events is facilitated by the erosion or rupture of vulnerable atherosclerotic plaques, which feature atrophic fibrous caps, large necrotic cores, accumulation of inflammatory cells and an imbalance between extracellular matrix synthesis and degradation (32-34). In the present study, PCS administration exacerbated the atherosclerotic burden of aortas in ApoE KO mice. In addition, collagen expression levels were significantly decreased in the atherosclerotic plaques of mice 
treated with PCS. PCS administration accelerated the progression of atherosclerosis and undermined plaque stability.

Leukocyte recruitment and vascular inflammation into lesions contribute to the initiation and progression of atherosclerosis (35-37). As a natural barrier, the vascular endothelium is crucial in inhibiting the adhesion of circulating inflammatory cells to the vessel wall (38). Endothelial cells express various adhesion molecules on their cell surface, including VCAM-1 and ICAM-1, the upregulation of which promotes leukocyte-endothelium interactions and facilitates the transendothelial migration of leukocytes (39). PCS, as an atherogenic stimulus, was predicted to promote leukocyte recruitment to vessel walls. The present study confirmed the enhanced leukocyte-endothelium adhesiveness using intravital microscopy. A potential mechanism underlying this phenomenon may be the upregulation of adhesion molecules, including VCAM-1 and ICAM-1.

Statins have been widely used in clinical practice for the management of dyslipidemia management in CKD patients and their potential in vessel protection has been confirmed $(40,41)$. In the present study, statin therapy significantly reversed the atherogenic effects of PCS. In addition, plaque stability was rescued by atorvastatin. Notably, these therapeutic effects are independent of its lipid-reduction effect. These findings emphasize the potential of statins as preventive and therapeutic treatments for atherosclerosis-associated CVD in CKD patients, particularly those with high PCS levels.

In conclusion, the results of the present study demonstrate that the uremic toxin PCS accelerates the progression of atherosclerosis and disturbs the stability of formed plaques. In addition, PCS upregulated the protein expression levels of adhesion molecules and enhanced the adhesiveness between leukocytes and endothelia. Furthermore, statin therapy was effective in abrogating these PCS-induced effects. The results of the present study provide novel insights into protein-bound uremic toxins, and the potential of statin therapy for cardiovascular complications in CKD. Patients with high levels of PCS may benefit from the direct vessel protection effects of statin treatment.

\section{Acknowledgements}

The present study was supported by the National Natural Science Foundation of China (grant nos. 81300178, 81370401 and 81500196).

\section{References}

1. McMahon GM, Hwang SJ and Fox CS: Residual lifetime risk of chronic kidney disease. Nephrol Dial Transplant: pii: gfw253, 2016.

2. Stenvinkel P: Chronic kidney disease: A public health priority and harbinger of premature cardiovascular disease. J Intern Med 268: 456-467, 2010.

3. Stojceva-Taneva O, Otovic NE and Taneva B: Prevalence of diabetes mellitus in patients with chronic kidney disease. Open Access Maced J Med Sci 4: 79-82, 2016.

4. Foley RN, Parfrey PS and Sarnak MJ: Clinical epidemiology of cardiovascular disease in chronic renal disease. Am J Kidney Dis 32 (5 Suppl 3): S112-S119, 1998.

5. Matsui M, Takeda Y, Uemura S, Matsumoto T, Seno A, Onoue K, Tsushima H, Morimoto K, Soeda T, Okayama S, et al: Suppressed soluble Fms-like tyrosine kinase-1 production aggravates atherosclerosis in chronic kidney disease. Kidney Int 85: 393-403, 2014
6. Go AS, Chertow GM, Fan D, McCulloch CE and Hsu CY: Chronic kidney disease and the risks of death, cardiovascular events, and hospitalization. N Engl J Med 351: 1296-1305, 2004.

7. Gluba-Brzózka A, Michalska-Kasiczak M, Franczyk B Nocuń M, Toth P, Banach M and Rysz J: Markers of increased atherosclerotic risk in patients with chronic kidney disease: A preliminary study. Lipids Health Dis 15: 22, 2016.

8. Roberts JK and McCullough PA: The management of acute coronary syndromes in patients with chronic kidney disease. Adv Chronic Kidney Dis 21: 472-479, 2014.

9. Di Angelantonio E, Chowdhury R, Sarwar N, Aspelund T, Danesh J and Gudnason V: Chronic kidney disease and risk of major cardiovascular disease and non-vascular mortality: Prospective population based cohort study. BMJ 341: c4986, 2010.

10. Hage FG, Venkataraman R, Zoghbi GJ, Perry GJ, DeMattos AM and Iskandrian AE: The scope of coronary heart disease in patients with chronic kidney disease. J Am Coll Cardiol 53: 2129-2140, 2009.

11. Martinez AW, Recht NS, Hostetter TH and Meyer TW: Removal of P-cresol sulfate by hemodialysis. J Am Soc Nephrol 16: 3430-3436, 2005.

12. Lekawanvijit S, Adrahtas A, Kelly DJ, Kompa AR, Wang BH and Krum H: Does indoxyl sulfate, a uraemic toxin, have direct effects on cardiac fibroblasts and myocytes? Eur Heart J 31: 1771-1779, 2010.

13. Wu IW, Hsu KH, Lee CC, Sun CY, Hsu HJ, Tsai CJ, Tzen CY, Wang YC, Lin CY and Wu MS: p-Cresyl sulphate and indoxyl sulphate predict progression of chronic kidney disease. Nephrol Dial Transplant 26: 938-947, 2011.

14. Liabeuf S, Barreto DV, Barreto FC, Meert N, Glorieux G, Schepers E, Temmar M, Choukroun G, Vanholder R and Massy ZA; European Uraemic Toxin Work Group (EUTox): Free p-cresylsulphate is a predictor of mortality in patients at different stages of chronic kidney disease. Nephrol Dial Transplant 25: 1183-1191, 2010.

15. Gansevoort RT, Correa-Rotter R, Hemmelgarn BR, Jafar TH, Heerspink HJ, Mann JF, Matsushita K and Wen CP: Chronic kidney disease and cardiovascular risk: Epidemiology, mechanisms, and prevention. Lancet 382: 339-352, 2013.

16. Kaluski E, Waller A, Patel A, Gerula C, Maher J, Haider B and Klapholz M: Clinical applicability of coronary atherosclerotic lesion characterization. Minerva Cardioangiol 59: 255-270, 2011.

17. Ruggeri ZM: Platelets in atherothrombosis. Nat Med 8: 1227-1234, 2002.

18. Nakamura K, Sasaki T, Cheng XW, Iguchi A, Sato K and Kuzuya M: Statin prevents plaque disruption in apoE-knockout mouse model through pleiotropic effect on acute inflammation. Atherosclerosis 206: 355-361, 2009.

19. Werner N, Nickenig G and Laufs U: Pleiotropic effects of HMG-CoA reductase inhibitors. Basic Res Cardiol 97: 105-116, 2002.

20. Feigenbaum J and Neuberg CA: Simplified method for the preparation of aromatic sulfuric acid esters. J Am Chem Soc 63: 3529-3530, 1941

21. Han H, Zhu J, Zhu Z, Ni J, Du R, Dai Y, Chen Y, Wu Z, Lu L and Zhang R: p-Cresyl sulfate aggravates cardiac dysfunction associated with chronic kidney disease by enhancing apoptosis of cardiomyocytes. J Am Heart Assoc 4: e001852, 2015.

22. Vanholder R, Schepers E, Pletinck A, Nagler EV and Glorieux G: The uremic toxicity of indoxyl sulfate and p-cresyl sulfate: A systematic review. J Am Soc Nephrol 25: 1897-1907, 2014.

23. Nie P, Li D, Hu L, Jin S, Yu Y, Cai Z, Shao Q, Shen J, Yi J, Xiao $\mathrm{H}$, et al: Atorvastatin improves plaque stability in ApoE-knockout mice by regulating chemokines and chemokine receptors. PLoS One 9: e97009, 2014.

24. Meng X, Zhang K, Li J, Dong M, Yang J, An G, Qin W, Gao F, Zhang $C$ and Zhang Y: Statins induce the accumulation of regulatory $\mathrm{T}$ cells in atherosclerotic plaque. Mol Med 18: 598-605, 2012 .

25. Wang XQ, Nigro P, World C, Fujiwara K, Yan C and Berk BC: Thioredoxin interacting protein promotes endothelial cell inflammation in response to disturbed flow by increasing leukocyte adhesion and repressing Kruppel-like factor 2. Circ Res 110: 560-568, 2012.

26. Wang XQ, Wan HQ, Wei XJ, Zhang Y and Qu P: CLI-095 decreases atherosclerosis by modulating foam cell formation in apolipoprotein E-deficient mice. Mol Med Rep 14: 49-56, 2016. 
27. Dong M, Yang X, Lim S, Cao Z, Honek J, Lu H, Zhang C, Seki T, Hosaka K, Wahlberg E, et al: Cold exposure promotes atherosclerotic plaque growth and instability via UCP1-dependent lipolysis. Cell Metab 18: 118-129, 2013.

28. Akhmedov A, Rozenberg I, Paneni F, Camici GG, Shi Y, Doerries C, Sledzinska A, Mocharla P, Breitenstein A, Lohmann C, et al: Endothelial overexpression of LOX-1 increases plaque formation and promotes atherosclerosis in vivo. Eur Heart J 35: 2839-2848, 2014.

29. Ouedraogo R, Gong Y, Berzins B, Wu X, Mahadev K, Hough K, Chan L, Goldstein BJ and Scalia R: Adiponectin deficiency increases leukocyte-endothelium interactions via upregulation of endothelia cell adhesion molecules in vivo. J Clin Invest 117: 1718-1726, 2007.

30. Zhou M, Ma C, Liu W, Liu H, Wang N, Kang Q and Li P: Valsartan promoting atherosclerotic plaque stabilization by upregulating renalase: A potential-related gene of atherosclerosis. J Cardiovasc Pharmacol Ther 20: 509-519, 2015.

31. Ross R: Atherosclerosis-an inflammatory disease. N Engl J Med 340: 115-126, 1999.

32. Haft JI: Multiple atherosclerotic plaque rupture in acute coronary syndrome. Circulation 107: e65-e66; author reply e65-e66, 2003.

33. Bergström G, Fagerberg B, Sallsten G, Lundh T and Barregard L: Is cadmium exposure associated with the burden, vulnerability and rupture of human atherosclerotic plaques? PLoS One 10: e0121240, 2015.

34. Zhang K, Meng X, Kong J, Liu FF, Yang JM, Gao F, Zhang Y and Zhang C: Simvastatin increases Prolyl-4-Hydroxylase $\alpha 1$ expression in atherosclerotic plaque and ox-LDL-stimulated human aortic smooth muscle cells via p38 MAPK and ERK1/2 signaling. J Mol Cell Cardiol 65: 43-50, 2013 .
35. Erbel C, Wolf A, Lasitschka F, Linden F, Domschke G, Akhavanpoor M, Doesch AO, Katus HA and Gleissner CA: Prevalence of M4 macrophages within human coronary atherosclerotic plaques is associated with features of plaque instability. Int J Cardiol 186: 219-225, 2015.

36. Molina-Sánchez P, Chèvre R, Rius C, Fuster JJ and Andrés V: Loss of p27 phosphorylation at Ser10 accelerates early atherogenesis by promoting leukocyte recruitment via RhoA/ROCK. J Mol Cell Cardiol 84: 84-94, 2015.

37. Hartwig H, Silvestre Roig C, Daemen M, Lutgens E and Soehnlein O: Neutrophils in atherosclerosis. A brief overview. Hamostaseologie 35: 121-127, 2015.

38. Inoue M, Ishida T, Yasuda T, Toh R, Hara T, Cangara HM, Rikitake Y, Taira K, Sun L, Kundu RK, et al: Endothelial cell-selective adhesion molecule modulates atherosclerosis through plaque angiogenesis and monocyte-endothelial interaction. Microvasc Res 80: 179-187, 2010.

39. Fu C, He J, Li C, Shyy JY and Zhu Y: Cholesterol increases adhesion of monocytes to endothelium by moving adhesion molecules out of caveolae. Biochim Biophys Acta 1801: 702-710, 2010.

40. Strippoli GF, Navaneethan SD, Johnson DW, Perkovic V, Pellegrini F, Nicolucci A and Craig JC: Effects of statins in patients with chronic kidney disease: Meta-analysis and meta-regression of randomised controlled trials. BMJ 336: 645-651, 2008.

41. Rysz J, Gluba-Brzózka A, Banach M and Więcek A: Should we use statins in all patients with chronic kidney disease without dialysis therapy? The current state of knowledge. Int Urol Nephrol 47: 805-813, 2015. 